\title{
Effect of dicarboxylic acid esters on the lubricity of aviation kerosene for use in $\mathrm{Cl}$ engines
}

\author{
G. ANASTOPOULOS ${ }^{1}$, S. KALLIGEROS ${ }^{2, *}$, P. SCHINAS ${ }^{1}$, F. ZANNIKOS ${ }^{1}$ \\ ${ }^{1}$ National Technical University of Athens, School of Chemical Engineering, Laboratory of Fuels Technology and Lubricants, Iroon \\ Polytechniou 9, Athens 15780, Greece \\ ${ }^{2}$ Hellenic Naval Academy, Laboratory of Fuels \& Lubricants Technology, End of Hatzikiriakou Avenue, Piraeus 18539, Greece \\ Received: 13 May 2013 / Revised: 08 July 2013 / Accepted: 22 August 2013 \\ C The author(s) 2013. This article is published with open access at Springerlink.com
}

\begin{abstract}
To reduce their fuel related logistic burden, North Atlantic Treaty Organization (NATO) Armed Forces are advancing the use of a single fuel for both aircraft and ground equipment. To this end, F-34 (the commercial equivalent is Jet A-1) is replacing distillate diesel fuel in many applications. However, tests conducted with this kerosene type on high frequency reciprocating rig showed that this type of fuel causes unacceptable wear. This excessive wear is caused by the poor lubricity of aviation fuel. In order to make this type of fuel compatible with direct injection compression engines, seven di-carboxylic acid esters have tested to improve the lubricity of kerosene. Tribological results showed that all esters tested in this series of experiments seem to be suitable for increasing the kerosene lubricity to a satisfactory level.
\end{abstract}

Keywords: lubricity; aviation kerosene; F-34; Jet A-1; compression ignition (CI) engines; dicarboxylic acid esters

\section{Introduction}

The idea of using one military fuel on the battlefield was conceived after the second world war, in order to simplify the logistic supply chain for petroleum products. Whilst two North Atlantic Treaty Organization (NATO) nations had converted to F-34 (comparable with commercial aviation fuel Jet A-1) in the mid-1960's, the move towards a single military fuel for the battlefield began in the 1970's when NATO Air Forces agreed to change their operating fuel from the wide cut F-40 (JP-4) to the safer, less flammable kerosene fuel F-34 (JP-8). One of the main reasons for this change was improved flight and ground based largely on US experiences during the Vietnam War [1].

In 1988, NATO nations decided to move towards the use of a single fuel (JP-8) for all land-based military aircraft, vehicles and equipment when employed on the European battlefield; this idea has become to be

* Corresponding author: S. KALLIGEROS.

E-mail: sskalligeros@hna.gr referred to as the single fuel concept (SFC) [2]. The logic behind such a decision comes not only from the gain of big logistical prizes in war time, but also from the more pragmatic fact of being able to both simplify and make better use of the NATO extensive and expensive pipeline system in times of peace [3]. The single fuel selected has been the F-34 (JP-8) military jet kerosene which is based upon the civil jet fuel F-35 (Jet A-1), which is widely available throughout the European Arena, with the inclusion of a military additive possessing anti-icing properties [4].

Prior to the decision, member nations of NATO have undertaken studies in order to identify problems that could arise in practice by the use of the kerosene based fuel in diesel engine vehicles (tanks, transporters, etc.) [5].

The accumulation of such experiences gained from these peace time studies was sufficient for the application of the concept to be tested in the war zone during the "Desert Storm" battle [6]. Although sufficient experience was gained, it was considered by NATO that further studies and exchange of 
experience should take place between the member nations in order to identify areas of development and activities required in order to better understand the engine operation with F-34 (JP-8) fuel; the latter one would eventually lead to resolving of the identified operational difficulties [7-9].

However, one main problem was identified in the process of implementing the SFC. In general, F-34 or the similar product F-35 showed a lower lubricity than commercial distillate diesel fuels. This may be because diesel fuel, having a higher boiling temperature range than kerosene, contains a larger proportion of naturally-occurring lubricity agents [10].

The objective of this work was to assess the lubricating properties of low sulfur diesel fuels additized with seven esters of mono-carboxylic acids of different structure. Data were generated to identify the minimum concentration of the above oxygen containing compounds, which provide lubricity improvement down to the $460 \mu \mathrm{m}$ wear scar diameter level. The value of $460 \mu \mathrm{m}$ was proposed by the European Committee for Standardization (CEN) in February 1997, and generally adopted by the industry, as the minimum requirement for an acceptable field performance [11].

Oxygen containing compounds such as fatty acids and their derivatives are superior friction reducing agents [12-24]. These compounds adsorb or react on rubbing surfaces to reduce adhesion between contacting asperities and limit friction, wear and seizure. Wei and Spikes considered that the significant wear reduction was produced by oxygen compounds with phenolic-type or carboxylic acid groups and occurred at a concentration of just a few parts per million [25]. On the other hand the use of oxygen containing fuels, such as esters, assists in the reduction of particulate matter emissions. More generally, it has been mentioned in the literature that the oxygen-carbon ratio $(\mathrm{O} / \mathrm{C})$ of a fuel significantly affects particulate emissions; so to achieve low smoke emissions (lower than 0.5 in the Bosch range), the $\mathrm{O} / \mathrm{C}$ ratio must be higher than 0.2 [26].

Although the impact of fatty acid esters on the lubricity of automotive diesel has been closely examined, their impact on the tribological properties of aviation fuels for use in compression ignition engines has not been examined in detail.

\section{Experimental procedure}

To assess the impact of the selected oxygen components on the lubrication properties of kerosene, an aviation fuel was obtained by a Greek refinery and was used for all the tribological experiments as a base fuel. The fuel properties are presented in Table 1, along with the standard methods that were used for their determination.

All tribological measurements were carried out using the high frequency reciprocating rig (HFRR) apparatus (Fig. 1), according to the CEC F-06-A-96 method. The test temperature was $60^{\circ} \mathrm{C}$ and the volume of the fuel sample used was $2 \mathrm{ml}$. Relative humidity was kept between $55 \%-58 \%$, while the mean ambient temperature was $24{ }^{\circ} \mathrm{C}$. The lubricating efficiency of the fuels was estimated by measuring the; photomicroscope. The wear scars quoted are corrected to give wear scar (WS) 1.4 values. The repeatability was calculated using the following equation [27]:

$$
R=139-(0.1648 \times \text { WS1.4 })
$$

The esters of di-carboxylic acids that were not

Table 1 Properties of aviation fuel.

\begin{tabular}{|c|c|c|}
\hline Fuel type & JP-8 & Method \\
\hline Density $\left(\mathrm{gr} / \mathrm{ml}, 15^{\circ} \mathrm{C}\right)$ & 0.7950 & ASTM D 1298 [28] \\
\hline Viscosity (cSt, $\left.-20^{\circ} \mathrm{C}\right)$ & 3,87 & ASTM D 445 [29] \\
\hline Flash point $\left({ }^{\circ} \mathrm{C}\right)$ & 41 & ASTM D 93 [30] \\
\hline Conductivity (pS/m) & 375 & ASTM D 2624 [31] \\
\hline Sulfur wt $\%$ & 0.23 & ASTM D 4294 [32] \\
\hline Aromatics vol\% & 15.3 & ASTM D 1319 [33] \\
\hline Olefins vol\% & 0.3 & ASTM D 1319 [33] \\
\hline \multicolumn{3}{|l|}{ Lubricity } \\
\hline Initial measurement $(\mu \mathrm{m})$ & 754 & \multirow[t]{2}{*}{ CEC F-06-A-96 [27] } \\
\hline $\begin{array}{l}\text { Repeated measurement } \\
\qquad(\mu \mathrm{m})\end{array}$ & 758 & \\
\hline \multicolumn{3}{|l|}{ Distillation $\left({ }^{\circ} \mathrm{C}\right)$} \\
\hline Ignition bioling point (IBP) & 145 & \multirow{5}{*}{ ASTM D 86 [34] } \\
\hline $10 \%$ & 174 & \\
\hline $20 \%$ & 181 & \\
\hline $50 \%$ & 200 & \\
\hline $90 \%$ & 233 & \\
\hline Final boiling point (FBP) & 250 & \\
\hline
\end{tabular}




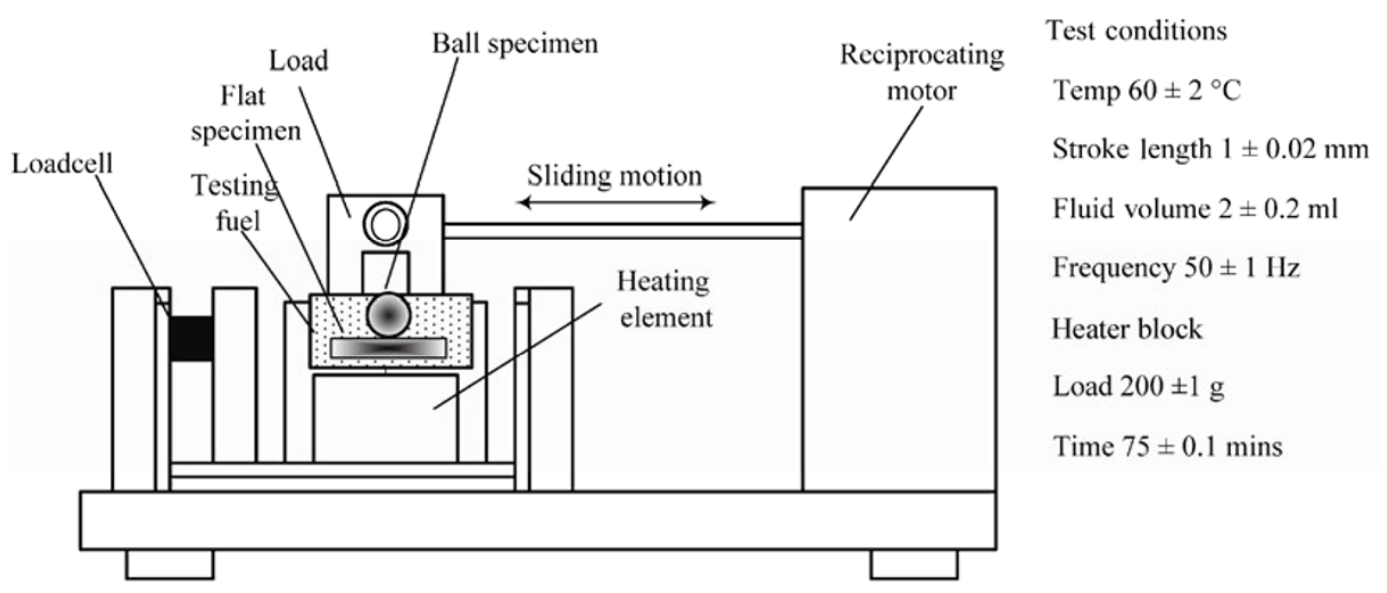

Fig. 1 Schematic diagram of lubricity test by high frequency reciprocating test rig.

commercially available were prepared by reacting di-chlorides of carboxylic acids with alcohols. The reaction can be expressed by the following equation:

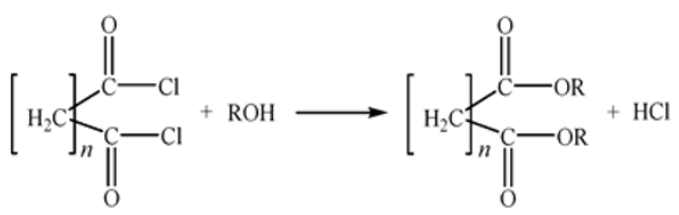

The alcohols and small excesses of triethylamine were dissolved in toluene, followed by the gradual addition of $0.7 \mathrm{~mol}$ equivalent of the acid di-chlorides with continuous stirring and cooling. The mixtures were stirred at room temperature for $24 \mathrm{~h}$. Afterward, they were washed with ice cold water, $\mathrm{HCl} 0.01 \mathrm{~N}$ and $5 \%$ aqueous sodium bicarbonate. The organic phases were dried over anhydrous sodium sulfate and finally the residues were distilled on a vacuum evaporator to receive the final products, whose properties were similar to those reported in the relevant literature [35-41]. In an effort to establish the purity of the prepared compounds, elemental analysis was carried out using the CHNS-O Carlo Erba EA1108 elemental analyzer of the laboratory, and the results are given in Table 2. The lack of structure indicator instrument keeps down any further information and transfers the continuation this part of the research for the near future. When the measured properties of the density $d_{4}{ }^{20}$, the refractive index $n_{\mathrm{D}}{ }^{20}$ (Table 3 ), and the elemental analysis are compared to the corresponding data found in literature, the purity level of the compounds eventually used in this study, was estimated to be at least $90 \%$.

The seven esters of di-carboxylic acids were dissolved to the base fuel, at the same concentration levels, i.e., $200,400,600,800,1,000,1200,1,400$, and 1,600 ppm.

Table 2 Elemental analysis of the oxygen compounds.

\begin{tabular}{ccccccc}
\hline \multirow{2}{*}{ Nomenclature } & \multicolumn{3}{c}{ Calculated content of $\mathrm{C}, \mathrm{H}, \mathrm{O}(\%)$} & \multicolumn{3}{c}{ Estimated content of C, $\mathrm{H}, \mathrm{O}(\%)$} \\
\cline { 2 - 7 } & $\mathrm{C}$ & $\mathrm{H}$ & $\mathrm{O}$ & $\mathrm{C}$ & $\mathrm{H}$ & $\mathrm{O}$ \\
\hline Dibutyl adipate & 65.1 & 10.1 & 24.8 & 64.9 & 10.1 & 24.7 \\
Dioctyl adipate & 71.3 & 11.3 & 17.3 & 71.6 & 11.5 & 17.1 \\
Diethyl azelate & 63.9 & 9.83 & 26.2 & 64.0 & 10.0 & 26.5 \\
Dibutyl azelate & 68.0 & 10.6 & 21.3 & 67.8 & 10.2 & 21.2 \\
Dioctyl azelate & 72.8 & 11.6 & 15.5 & 73.1 & 11.7 & 15.5 \\
Diethyl sebacate & 65.1 & 10.1 & 26.8 & 64.9 & 10.4 & 26.7 \\
Bis(2-ethyl-hexyl) sebacate & 73.2 & 11.7 & 15.0 & 73.1 & 11.5 & 14.8 \\
\hline
\end{tabular}


Table 3 Characteristics of the oxygen compounds.

\begin{tabular}{ccccccc}
\hline Nomenclature & $\begin{array}{c}\text { Chemical } \\
\text { structure }\end{array}$ & $\begin{array}{c}\text { Molecular } \\
\text { weight }\end{array}$ & $\begin{array}{c}\text { Measured } \\
\text { density, } d_{4}{ }^{20}\end{array}$ & $\begin{array}{c}\text { Density of pure } \\
\text { ester, } d_{4}^{20}\end{array}$ & $\begin{array}{c}\text { Measured refractive } \\
\text { index, } n_{\mathrm{D}}{ }^{20}\end{array}$ & $\begin{array}{c}\text { Refractive index } \\
\text { of pure ester, } n_{\mathrm{D}}{ }^{20}\end{array}$ \\
\hline Dibutyl adipate & $\mathrm{C}_{14} \mathrm{H}_{26} \mathrm{O}_{4}$ & 258 & 0.941 & $0.945[35]$ & 1.4364 & $1.4358[35]$ \\
Dioctyl adipate & $\mathrm{C}_{22} \mathrm{H}_{42} \mathrm{O}_{4}$ & 370 & 0.930 & $0.925[36]$ & 1.4478 & $1.4471[36]$ \\
Diethyl azelate & $\mathrm{C}_{13} \mathrm{H}_{24} \mathrm{O}_{4}$ & 244 & 0.968 & $0.973[37]$ & 1.4356 & $1.4350[37]$ \\
Dibutyl azelate & $\mathrm{C}_{17} \mathrm{H}_{32} \mathrm{O}_{4}$ & 300 & 0.942 & $0.947[38]$ & 1.4412 & $1.4406[38]$ \\
Dioctyl azelate & $\mathrm{C}_{25} \mathrm{H}_{48} \mathrm{O}_{4}$ & 412 & 0.913 & $0.918[39]$ & 1.4518 & $1.4510[39]$ \\
Diethyl sebacate & $\mathrm{C}_{14} \mathrm{H}_{26} \mathrm{O}_{4}$ & 258 & 0.991 & $1.007[40]$ & 1.4369 & $1.4360[40]$ \\
$\begin{array}{c}\text { Bis(2-ethyl-hexyl) } \\
\text { sebacate }\end{array}$ & $\mathrm{C}_{26} \mathrm{H}_{50} \mathrm{O}_{4}$ & 426 & 0.924 & $0.919[41]$ & 1.4516 & $1.4510[41]$ \\
\hline
\end{tabular}

\section{Results and discussion}

The base fuel was initially analyzed to determine its lubrication effectiveness. The corrected wear scar diameter (WSD) value for the base fuel, on the first day of its production, is cited in Table 1 . It is evident that the fuel has a wear scar diameter value much higher than the acceptable limit of $460 \mu \mathrm{m}$, and was characterized as fuel with poor lubricating properties. Repeated tribological measurement on the next day confirmed this conclusion. Consequently, this fuel was well suited to determine the lubricity of additives.

Figure 2 gives, in graphical form, the effect of the addition of dibutyl adipate on the WS1.4 of the base fuel. Small concentrations of dibutyl adipate that

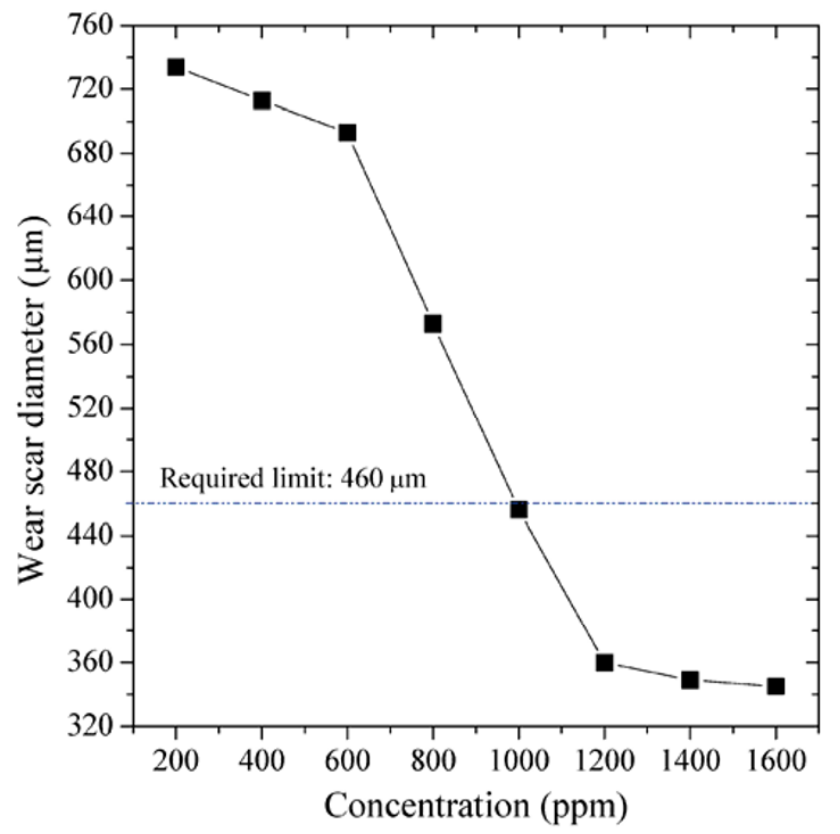

Fig. 2 Impact of dibutyl adipate addition on the lubrication properties of the F-34 military jet kerosene. ranged between 200 and 600 ppm practically caused no alteration on the corrected wear scar diameter of the base fuel. A substantial increase of the lubrication performance was shown with the addition of the dibutyl adipate under observation in the concentration of $800 \mathrm{ppm}$. Yet, even in this case, the limit of $460 \mu \mathrm{m}$ was not satisfied. When dealing with the increase of the concentration of dibutyl adipate from 800 to $1,000 \mathrm{ppm}$, it was observed that there was an increasing effect on the lubricity of the base fuel, thus decreasing the wear scar diameter by $4 \mu \mathrm{m}$ under the acceptable limit. For concentrations of dibutyl adipate between 1,200 and 1,600 ppm the decrease in the WSD values was small, and the fuel attained a constant wear scar diameter value of approximately $350 \mu \mathrm{m}$.

The impact of dioctyl adipate on the lubricity of the base fuel is outlined in Fig. 3. When analyzing the results, it is observed that the addition of dioctyl adipate in the concentrations between 200 and 600 ppm even though it increased the lubricity of the base fuel, it did not reach the acceptable limit value of $460 \mu \mathrm{m}$. The desired improvement was realized as there was an increase in the concentration of dioctyl adipate from 600 to 800 where the maximum permissible HFRR mean wear scar diameter of $460 \mu \mathrm{m}$, required for commercial diesel fuels was satisfied. Comparing the tribological results of dioctyl adipate with those of dibutyl adipate, it is observed that the first has a better lubricating behavior on the base fuel.

Figure 4 shows the influence of diethyl azelate on the lubrication properties of the base fuel. On the basis of the HFRR test results, the addition of diethyl azelate at the concentration levels lower than 1,000 ppm 


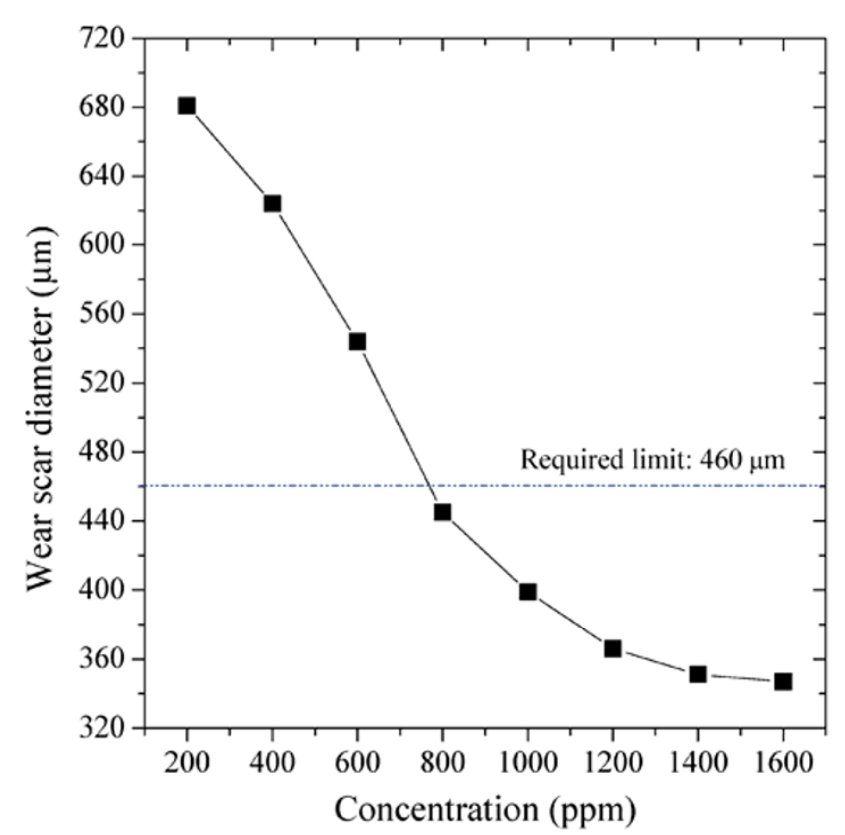

Fig. 3 Impact of dioctyl adipate addition on the lubrication properties of the F-34 military jet kerosene.



Fig. 4 Impact of diethyl azelate addition on the lubrication properties of the F-34 military jet kerosene.

does not seem capable to increase the lubricity of the fuel to an acceptable level. Contrary, a significant reduction on the WS1.4 to under the limit of $460 \mu \mathrm{m}$ is observed when 1,000 ppm of diethyl azelate is added, whereas extra addition of same dicarboxylic acid ester seems to offer even better improvement on the lubrication properties of the base fuel. Thus, for concentrations between 1,200 and 1,600 ppm, the WSD illustrates an even higher decline, reaching $331 \mu \mathrm{m}$.

Figure 5 depicts the impact of the addition of dibutyl azelate on the base fuel lubricity. As in the case of diethyl azelate (Fig. 3), similarly here, the required treat rate to obtain a satisfactory wear scar diameter (WS1.4) of $460 \mu \mathrm{m}$ was 1,000 ppm. However, a higher dosage of dibutyl azelate led to a slight increase of the fuel lubricity. The careful assessment of the experimental results leads to the realization that dibutyl azelate presents a slightly improved lubrication performance than diethyl azelate. Even though, both types of dicarboxylic acid esters provide an acceptable level of performance at a $1,000 \mathrm{ppm}$, however at this concentration level, the corrected wear scar diameter of diethyl azelate was $442 \mu \mathrm{m}$, while the WSD value of the dibutyl azelate was $429 \mu \mathrm{m}$. Thus the second dicarboxylic acid ester had a slightly better lubrication performance.

Figure 6 presents the dependence of the base fuel lubricity on the concentration of dioctyl azelate. Although its addition at concentrations lower than 800 ppm did not seem capable to set the WS1.4 value well within the required limit, however a notable improvement in the fuel lubricity was observed with

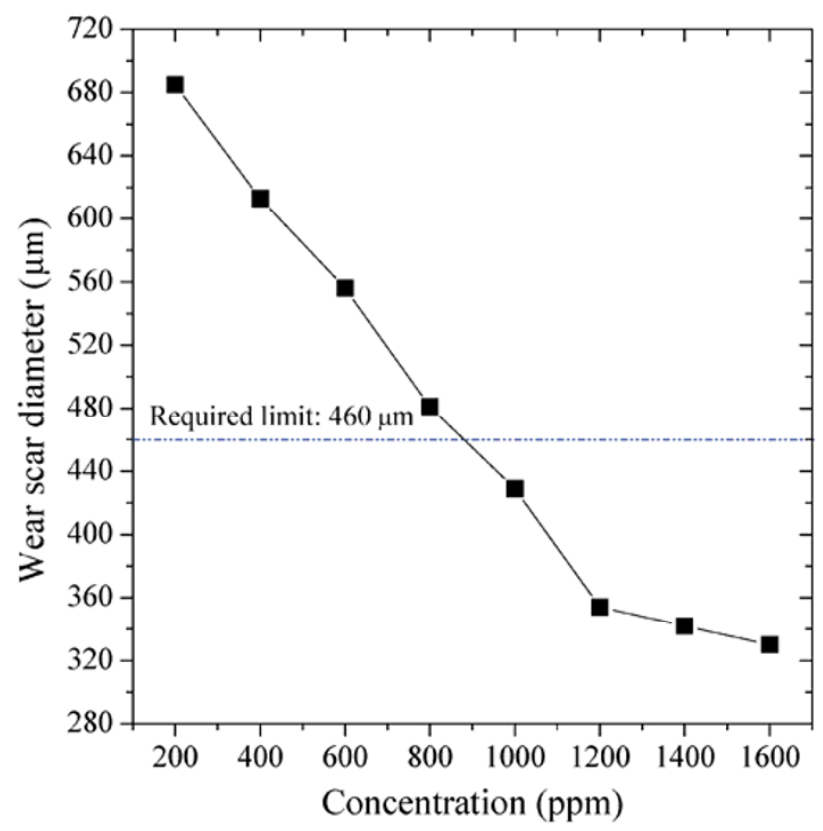

Fig. 5 Impact of dibutyl azelate addition on the lubrication properties of the F-34 military jet kerosene. 


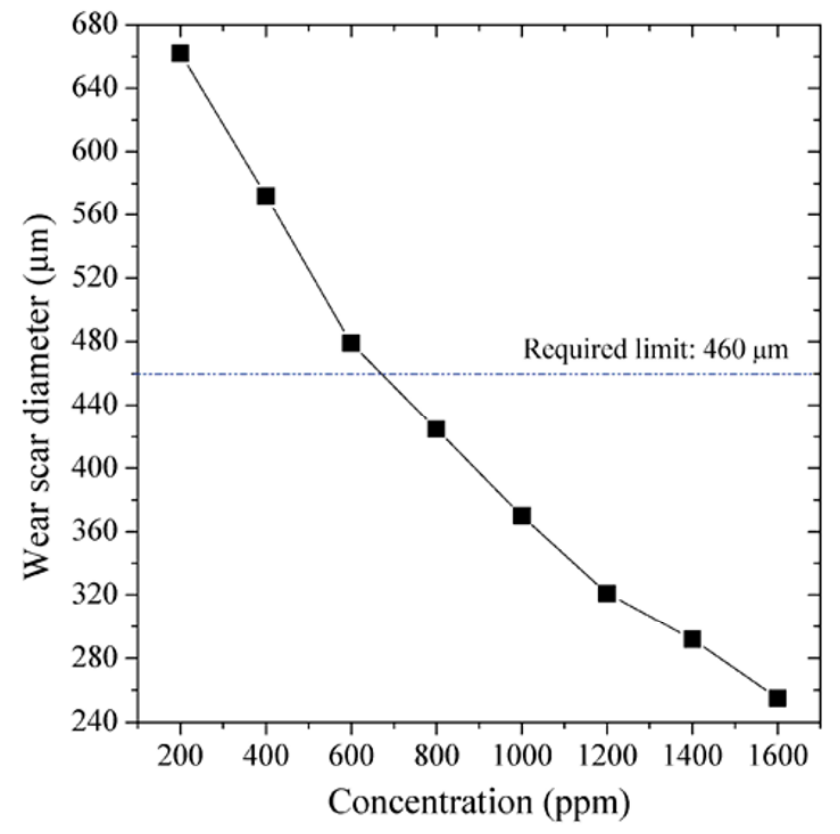

Fig. 6 Impact of dioctyl azelate addition on the lubrication properties of the F-34 military jet kerosene.

the addition of $800 \mathrm{ppm}$ of dioctyl azelate, where the wear scar diameter was decreased to $425 \mu \mathrm{m}$. It should also be noted that this ester presented the best effect on the lubrication properties of the base fuel from any other type of dicarboxylic acid ester that was examined.

Figures 7 and 8 illustrate the lubricity improveement due to the addition of diethyl sebacate and bis(2-ethyl-hexyl) sebacate to the base fuel. Here the required treat rates to obtain a satisfactory wear scar diameter (WS1.4) of $460 \mu \mathrm{m}$, were 1,000 and $800 \mathrm{ppm}$ respectively.

It is evident that, in order to improve the lubrication properties of kerosene, small concentration levels of di-carboxylic esters ranging from $800-1,000$ ppm, were necessary to bring the wear scar diameter value within the required limit, and any extra addition of di-carboxylic acid esters, did not give any significant improvement in the lubricity of the fuels.

Although, all types of the di-carboxylic esters tested in this series of experiments, had a beneficial impact on the lubricity of kerosene, an interesting conclusion is derived from the comparison of diesters produced from the same di-carboxylic acid. Among the diesters derived from the same di-carboxylic acid, i.e. the adipate and azelate series, an increase of the

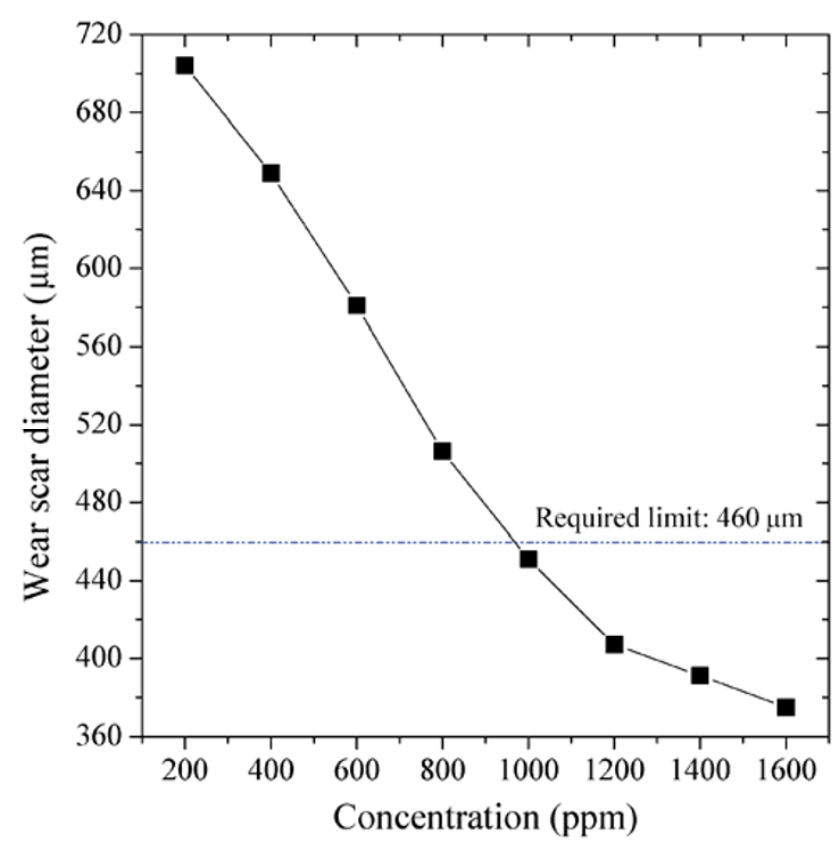

Fig. 7 Impact of diethyl sebacate addition on the lubrication properties of the F-34 military jet kerosene.

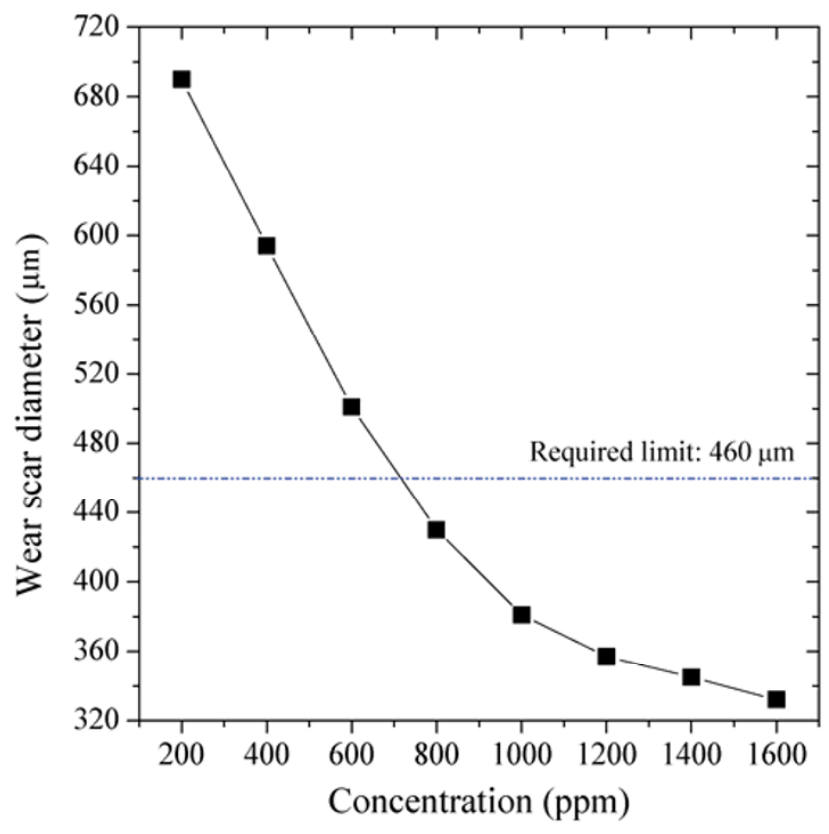

Fig. 8 Impact of bis(2-ethyl-hexyl) sebacate addition on the lubrication properties of the F-34 military jet kerosene.

chain length of the alcohol involved in the esterification reaction, namely from diethyl to dibutyl and dioctyl alcohol, leads to a higher lubrication performance; conversely, if the chain length of the alcohol is kept constant, an increase in dicarboxylic 
acid chain length does not cause significant improveement in lubricity.

\section{Conclusions}

In an effort to investigate the impact of monocarboxylic acid esters on the tribological properties of kerosene, seven esters were added to a military aviation fuel JP-8. The following conclusions can be drawn from this study:

1. Current aviation kerosene, when used in army ground vehicles as part of the single fuel concept, does not provide satisfactory lubrication and may lead to damage in the fuel pumps of the engines.

2. Small concentration levels of the mono-carboxylic acid esters ranging from $800-1,000$ ppm, were necessary to bring the wear scar diameter value within the required limit of $460 \mu \mathrm{m}$, and any extra addition of the esters, did not give any significant improvement in the lubricity of the fuels.

3. Among the esters of the same molecular type, those having the ester group around the middle of the molecule appear to give a better lubrication performance.

Open Access: This article is distributed under the terms of the Creative Commons Attribution License which permits any use, distribution, and reproduction in any medium, provided the original author(s) and source are credited.

\section{References}

[1] Batchelor C, Moses C, Fletcher R. Impact study on the use of Jet-A fuel in military aircraft during operations in Europe. AGARD-R-801, Canada Communication Group, 1997.

[2] Garrett R K. Is a single fuel on the battlefield still a viable option? Executive Research Project, S27 The Industrial College of the Armed Forces, National Defense University Fort McNair, Washington D.C., 1993.

[3] Goss D E. 10,000 mile JP-8 test of 6.2 litre diesel engine in M1028 CUCV vehicles. Final Report, General Motors Corporation, Military Vehicles Operation, 1987.

[4] Likoos W E, Owens E C, Lestz S J. Laboratory evaluation of Mil-T-83133 JP-8 fuel in army diesel engines. BELRF Report No. 232, Belvoir Fuels and Lubricants Research Facility, San Antonio, Texas, 1988.
[5] Bowden J N, Westbrook S R, LePore M E. Jet kerosene fuels for military diesel applications. SAE Paper 892070 (1989)

[6] Papagiannakis R G, Kotsiopoulos P, Yfantis E, Hountalas D. Single fuel research program comparative results of the use of JP-8 aviation fuel versus diesel fuel on a direct injection diesel engine. SAE Paper 2006-01-1673 (2006)

[7] Fletcher R S. The Single Fuel Concept and Operation Desert Shield/Storm: A Report of a Special Meeting Convened by the Fuels Standing Committee (SC03) of the Propulsion and Energetics Panel of AGARD. Paris (France): AGARD, 1994.

[8] Belvoir R - D \& E Centre. JP-8 single fuel forward report. U.S. Army, 1991.

[9] North Atlantic Treaty Organization. Proposals for solutions to problems related to the use of F-34 (SFP) and high sulphur diesel on ground equipment using advanced reduction emission technologies. RTO NATO.

[10] Bader J. Tribological evaluation of kerosene as substitute for distillate diesel fuel. In proceedings of $2^{\text {nd }}$ International Colloquium, Esslingen, Germany, 1999: 239-252.

[11] European Committee for Standardization (CEN). Specification automotive diesel. In $14^{\text {th }}$ Meeting, Vienna, Austria, 1997.

[12] Hertz P B. Summer' 95 engine wear investigations using canola methyl ester and No. 2 diesel fuels. Canodev research Inc. Saskatoon SK, Canada, 1996.

[13] Galbraith R M, Hertz P B. The Rocle test for diesel and biodiesel fuel Lubricity. SAE Paper 972862 (1997)

[14] Karonis D, Anastopoulos G, Lois E, Stournas S, Zannikos F, Serdari A. Assessment of the lubricity of Greek road diesel and the effect of the addition of specific types of biodiesel. SAE Paper 1999-01-1471 (1999)

[15] Anastopoulos G, Lois E, Serdari A, Zanikos F, Stournas S, Kalligeros S. Lubrication properties of low-sulfur diesel fuels in the presence of specific types of fatty acid derivatives. Energ Fuel 15: 106-112 (2001)

[16] Anastopoulos G, Lois E, Karonis D, Zanikos F, Stournas S, Kalligeros S. A preliminary evaluation of esters of monocarboxylic acids on the lubrication properties of low sulfur diesel fuels. Ind Eng Chem Res 40: 452-456 (2001)

[17] Kajdas C, Majzner M. The influence of fatty acids and fatty acids mixtures on the lubricity of low-sulfur diesel fuels. SAE Paper 2001-01-1929 (2001)

[18] Geller D P, Goodrum J W. Effect of specific fatty acid methyl ester on diesel fuel lubricity. Fuel 83: 2351-2356 (2004)

[19] Schumacher L G, Adams B T. Using biodiesel as a lubricity additive for petroleum diesel fuel. ASAE Paper 02-6085 (2002)

[20] Goodrum J W, Geller D P. Influence of fatty acid methyl esters from hydroxylated vegetable oils on diesel fuel lubricity. Bioresour Technol 96: 851-855 (2005)

[21] Bhuyan S, Sundararajan S, Yao L, Hammond E G, Wang T. Boundary lubrication properties of lipid-based compounds 
evaluated using microtribological methods. Tribol Lett 22: 2-11 (2006)

[22] Wadumesthrige K, Ara M, Salley S O, Simon Ng K Y. Investigation of lubricity characteristics of biodiesel in petroleum and synthetic fuel. Energ Fuel 23: 2229-2234 (2009)

[23] Hu J, Du Z, Li C, Min E. Study on the lubrication properties of biodiesel as fuel lubricity enhancers. Fuel 84: 1601-1606 (2005)

[24] Knothe G, Steidley K R. Lubricity of components of biodiesel and petrodiesel. The origin of biodiesel lubricity. Energ Fuel 19: 1192-1200 (2005)

[25] Wei D, Spikes H. The lubricity of diesel fuels. Wear 111: 217-235 (1986)

[26] Hashimoto T, Akasaka Y. Evaluation of qxygenated fuels using conventional and a new type of diesel engines. In Proceedings of the Ninth International Symposium on Alcohol Fuels, Firenze, Itlay, 1991: 336-341.

[27] CEC F-06-A-96: Measurement of diesel fuel lubricityapproved test method. HFRR Fuel Lubricity Test.

[28] Standard test method for density, relative density, or API gravity of crude petroleum and liquid petroleum products by hydrometer method. ASTM D1298, 2012.

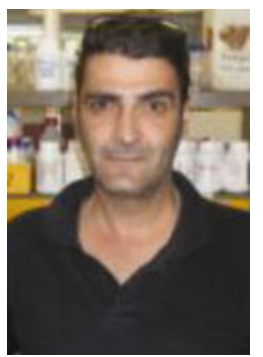

G. ANASTOPOULOS. He received his Ph. D degree in Fuels \& Lubricants Technology from National Technical University of Athens, Greece, in 2002. His current position is research associate in Laboratory of Fuels \&

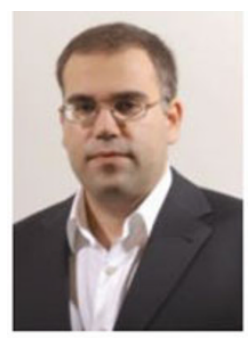

S. KALLIGEROS. He received his Bachelor degree in Mechanical Engineering from National Technical University of Athens, Greece, in 1996, MS degree in Energy Management \& Environmental Protection from University of Piraeus, Greece, in 2000 and Ph.D degree in Fuels \& Lubricants Technology from National Technical University of Athens, Greece, in 2002. After a career in Industrial and Public sector he joined the Laboratory of Fuels \&
[29] Standard test method for kinematic viscosity of transparent and opaque liquids (and calculation of dynamic viscosity). ASTM D445, 2011.

[30] Standard test methods for flash point by Pensky-Martens closed cup tester. ASTM D93, 2012.

[31] Standard test methods for electrical conductivity of aviation and distillate fuels. ASTM D2624, 2009.

[32] Standard test method for sulfur in petroleum and petroleum products by energy dispersive X-ray fluorescence spectrometry. ASTM D4294, 2010.

[33] Standard test method for hydrocarbon types in liquid petroleum products by fluorescent indicator adsorption. ASTM D1319, 2010.

[34] Standard test method for distillation of petroleum products at atmospheric pressure. ASTM D86, 2012.

[35] Beilstein Handbuch der Organichen Chemie 3, III, 1203.

[36] Beilstein Handbuch der Organichen Chemie 2, II, 575.

[37] Beilstein Handbuch der Organichen Chemie 2, 709, II, 603.

[38] Beilstein Handbuch der Organichen Chemie 2, 1787.

[39] Beilstein Handbuch der Organichen Chemie 2, II, 609.

[40] Beilstein Handbuch der Organichen Chemie 2, 719, III, 1807.

[41] Beilstein Handbuch der Organichen Chemie 2, III, 1810.

Lubricants Technology of the School of Chemical Engineer at National Technical University of Athens. His research areas cover the tribology of fuels and fuel additives, biofuels tribological characteristics, production of biofuels, biolubricants.

Lubricants Technology at Hellenic Naval Academy from 2010. His current position is a lecturer and responsible for the Operation of the laboratory. He is also the technical convenor of Hellenic Organization for Standardization (ELOT) Committee for Fuels, Lubricants \& Petrochemical Industry from 2006. His research areas cover the impacts of fuels in engine performance and in the environment, biofuels, biolubricants, standardization of fuels and lubricants, quality assurance. 